\title{
IDENTIFICAÇÃO DA INFLUÊNCIA DO DESCARTE DE LODO DE ESTAÇÕES DE TRATAMENTO DE ÁGUA
}

Edson Luís Tocaia dos Reis, Marycel Elena Barbosa Cotrim, Cláudio Rodrigues e Maria Aparecida Faustino Pires* Instituto de Pesquisas Energéticas e Nucleares, CP 11049, 05422-970 São Paulo - SP, Brasil

\section{Osvaldo Beltrame Filho}

Setor de Controle Sanitário, Companhia Saneamento Básico do Estado de São Paulo, Rua Joaquim M. Alves, 1002, 11900-000

Registro - SP, Brasil

Solange Martone Rocha e Silvana Audrá Cutolo

Departamento de Saúde Ambiental, Faculdade de Saúde Pública, Universidade de São Paulo, Av. Dr. Arnaldo, 715, 01246-904

São Paulo - SP, Brasil

Recebido em 2/5/06; aceito em 29/9/06; publicado na web em 28/5/07

\begin{abstract}
IDENTIFICATION OF THE INFLUENCE OF SLUDGE DISCHARGES FROM WATER TREATMENT PLANTS. The growing concern of environmental surveillance of the quality of hydric resources guides the development of research on management of residues generated in water treatment plants (WTP). Approximately 8.000 WTPs in Brazil operate without a treatment program of the residues, disposing these effluents in the environment. This work evaluated WTP discharges into watercourses by collecting superficial waters, sediments and benthic samples at the town of Registro, São Paulo State, Brazil. Even though superficial waters and benthic samples showed no further contamination, sediment analysis pointed out that aluminum deposits detected near sludge discharges may represent a potential risk to the environment.
\end{abstract}

Keywords: sludge; water treatment plant; Vale do Ribeira basin.

\section{INTRODUÇÃO}

O processo de crescimento econômico do Brasil iniciado a partir da década de 50 demandou a implantação de políticas governamentais para o setor de saneamento básico, propiciando uma infra-estrutura necessária para a melhoria de vida da população, como sistemas de tratamento de água e esgotos. No entanto, apesar de serem controladas por empresas públicas de saneamento, as estações de tratamento de água e esgotos são consideradas fontes pontuais de poluição, por gerarem resíduos sólidos (lodo) como subprodutos do próprio processo de tratamento. Por falta da adoção de políticas específicas de gerenciamento, os resíduos produzidos em estações de tratamento de água têm sido dispostos de forma ambientalmente inadequada em cursos d'água ou galerias de águas pluviais ${ }^{1}$.

Dentre os municípios avaliados no último censo com mais de 300.000 habitantes, $85,7 \%$ possuem estações de tratamento de água (ETAs) que a tratam antes de ser distribuída à população. Deste subtotal, aproximadamente $50 \%$ dos municípios possuem sistemas de tratamento do tipo convencional, gerando resíduos insolúveis que são destinados em sua maioria diretamente ao meio ambiente (rio, mar e terreno) $)^{2}$. Esse processo de descarte pode alterar consideravelmente as características das águas do corpo receptor, provocando assoreamento e mudança na cor, turbidez e composição química, além da possibilidade de contaminação do lençol freático ${ }^{3,4}$. Se considerarmos que milhões de toneladas desses resíduos são dispostos anualmente no ambiente, podemos classificar os lodos formados como um subproduto com potencial poluidor, devido a seus efeitos químicos, físicos e biológicos ${ }^{1}$.

Alternativas para o destino final do lodo de ETAs têm sido propostas, como a disposição em aterros sanitários, aterros exclusivos, gerenciamento conjunto com lodo de tratamento de esgoto e codisposição com biosólido, aplicação controlada em certos tipos de

\footnotetext{
*e-mail: mapires@ipen.br
}

solo, em matriz de concreto ${ }^{5,6}$ e, aplicações industriais diversas ${ }^{1,7}$. Por outro lado, o lançamento do lodo de ETAs nos cursos d'água vem sendo drasticamente reduzido, como consequiência de legislações mais rigorosas de controle da poluição e da crescente escassez dos recursos hídricos, captados cada vez mais distantes e a custos elevados, adaptando estes efluentes a um novo modelo de gerenciamento de resíduos ${ }^{8}$. Nesse sentido, o gerenciamento adequado dos sistemas de tratamento de águas para abastecimento público deve também abranger todos os problemas relacionados à proteção dos mananciais, qualidade dos produtos químicos empregados e as consequiências do descarte sistemático desses resíduos.

O principal objetivo deste trabalho foi avaliar os efeitos do descarte dos resíduos gerados em uma ETA em corpos d'água. Para isso, foi escolhida uma ETA na cidade de Registro, localizada na bacia hidrográfica do rio Ribeira de Iguape, no estado de São Paulo9. Foram avaliadas amostras de água, sedimentos e organismos bentônicos coletados a montante e jusante do descarte da ETA. Este estudo é parte integrante do projeto de pesquisa com financiamento Fapesp Políticas Publicas no. 03/06419-1: "Gerenciamento de Lodos de ETAs. Influência do Lançamento do Lodo de ETA no Processo de Tratamento de Esgotos por Lagoas de Estabilização em Cidades de Pequeno Porte", realizado em parceria do Instituto de Pesquisas Energéticas e Nucleares (IPEN) com a Companhia de Saneamento Básico do Estado de São Paulo (SABESP) e a Escola Politécnica da Universidade de São Paulo (Poli/USP).

\section{PARTE EXPERIMENTAL}

\section{Área de estudo}

A bacia hidrográfica do rio Ribeira de Iguape situa-se aproximadamente entre as latitudes $23^{\circ} 50^{\prime} \mathrm{e} 25^{\circ} 30^{\prime}$ Sul e longitude $46^{\circ} 50^{\prime} \mathrm{e}$ $50^{\circ} 00^{\prime}$ 'Oeste, abrangendo uma área de $24.980 \mathrm{~km}^{2}$, dos quais $61 \%$ pertencem ao estado de São Paulo e 39\% ao estado do Paraná. O rio 
Ribeira de Iguape nasce no estado do Paraná a uma altitude de 1.000 $\mathrm{m}$, permanecendo com o nome de rio Ribeira até a cidade de Eldorado, no estado de São Paulo. Apresenta uma extensão de aproximadamente $470 \mathrm{~km}$, sendo $120 \mathrm{~km}$ em terras paranaenses, com sua foz localizada no município de Iguape. Abrange 32 municípios, sendo 9 no estado do Paraná e 23 no estado de São Paulo. Em geral, são cidades de porte pequeno com destaque para Registro, Iguape, Apiaí, Juquitiba e Juquiá, na parte paulista, e Rio Branco do Sul, na parte paranaense. Juntamente com o Complexo Estuário Lagunar de Iguape, Cananéia e Paranaguá, compõe o denominado Vale do Ribeira, com extensão de $260 \mathrm{~km}$ e $140 \mathrm{~km}$ de costa para o Oceano Atlântico, e uma população estimada em 400 mil habitantes ${ }^{10}$.

A região é reconhecida pela UNESCO como patrimônio ambiental da humanidade, que se traduz em mais de 2,1 milhões de ha de florestas (aproximadamente $21 \%$ da área remanescente de Mata Atlântica do Brasil), protegidas pela criação de 7 parques estaduais, 2 estações ecológicas e 3 áreas de preservação. A preservação dos ecossistemas naturais, no entanto, restringe o uso econômico de diversas atividades na região, cujos parâmetros socioeconômicos e demográficos, tais como mortalidade infantil, condições de habitação e níveis de renda e de escolaridade, contribuem para que a região apresente o menor índice de desenvolvimento humano (IDH) do estado $^{11}$. A Lei Estadual no ${ }^{\circ}$. 7.663/91 decretou a instalação do Comitê da Bacia Hidrográfica do Ribeira de Iguape e Litoral Sul - CBD RB, com o objetivo de gerenciar os recursos hídricos e sua preservação, na Unidade de Gerenciamento de Recursos Hídricos (UGRHI-11), onde se encontram 18 ETAs operadas pela SABESP, que atendem parte do consumo de água tratada da região ${ }^{12}$.

Avaliações realizadas nos últimos anos nos aqüíferos do Vale do Ribeira têm identificado diversas áreas críticas em termos de risco de potencial de contaminação. A CETESB constatou em 1999 uma não conformidade de metais tóxicos $(\mathrm{Cu}$ e $\mathrm{Ni})$, apesar de não relacionada às atividades mineradoras de Registro ${ }^{13}$. A análise de coliformes fecais entre 1989 a 2000 indicou a ocorrência de lançamentos de esgotos domésticos clandestinos como o maior comprometimento das águas nessa cidade ${ }^{14}$.

Embora resultados do IAP (Índice de qualidade das águas para fins de abastecimento público) apontaram os rios Ribeira, Ribeira de Iguape e Juquiá como rios de qualidade boa, o rio Jacupiranga apresentou classificação regular, com teores elevados de alumínio, manganês, ferro e fósforo total, detectando-se toxidade para a Ceriodaphnia dubia e indicando a necessidade de uma investigação mais profunda na região. Pontos de coleta no rio Ribeira de Iguape também apresentaram altas concentrações de fósforo, além da presença de $\mathrm{Pb}$ em sedimentos do próprio rio Ribeira de Iguape, no trecho de Iporanga, com provável origem nas antigas minerações de chumbo do Paraná. Foi encontrada uma concentração ele- vada do elemento (133 $\mathrm{mg} \mathrm{kg}^{-1}$ ), superior à PEL (probabilidade de efeito severo à biota) ${ }^{15}$, e mais elevada que os resultados de contaminantes em sedimentos obtidos em $2003^{16}$.

Por outro lado, apesar da maioria dos resultados dos testes de toxicidade indicar ausência de substâncias tóxicas nas águas, é necessário manter ações de controle ambiental, uma vez que a poluição das águas da região pode comprometer o abastecimento público de algumas cidades ${ }^{9,16,17}$. Tal preocupação se justifica em razão da carga de lodos de ETAs dos municípios da região lançados no Rio Ribeira de Iguape, que representa uma importante fonte de captação de água para abastecimento público ${ }^{18}$.

\section{Coleta e amostragem de águas superficiais e sedimentos}

As amostras de águas superficiais e sedimentos coletadas durante o período de avaliação consideraram os prováveis caminhos do poluente em potencial no ambiente de estudo, de forma a apresentarem informações sobre os processos de degradação do ecossistema pelo contato direto com o efluente. Metais em níveis de traços, por ex., depois de serem lançados em ambientes aquáticos podem encontrar-se distribuídos na água, no sedimento, além da biota, por incorporação de poluentes nos organismos aquáti$\cos ^{19}$. Deste modo, as estações de amostragem nos cursos de água foram definidas a montante e jusante do descarte da ETA, de forma a se verificar as características naturais da área e avaliar o potencial de comprometimento dos despejos da ETA. Os pontos de coleta foram identificados por convenções, conforme apresentado na Tabela 1 e mostrados de forma esquemática na Figura 1. Foram coletadas 1 vez ao mês amostras de água e sedimento recolhidas 24 h após o descarte do lodo, no período entre dezembro de 2003 e agosto de 2004, abrangendo o período de chuvas e estiagem. Foram também realizadas 3 amostragens de organismos bentônicos (setembro e outubro de 2004 e abril de 2005).

As coletas das amostras foram realizadas conforme recomendação do guia de coletas da CETESB ${ }^{20}$ e do "Standard Methods"21, considerando o tipo de frasco para cada parâmetro, volume necessário para análise, preservação de amostra e prazo para a realização da análise de cada parâmetro. O procedimento utilizado para a preservação de amostras de água foi sob refrigeração à $4{ }^{\circ} \mathrm{C}$. Para a determinação de metais, as amostras foram filtradas e preservadas com a adição de solução de $\mathrm{HNO}_{3} 1: 1$ até $\mathrm{pH}<2$. As amostras de água bruta foram coletadas a aproximadamente $10 \mathrm{~cm}$ da superfície em frascos de polietileno. As amostras de sedimento foram coletadas em aproximadamente $30-50 \mathrm{~cm}$ de profundidade utilizando-se uma draga do tipo Ekman-Birge, com área igual a $22,5 \mathrm{~cm}^{2}$. Em alguns casos, devido à dificuldade de coleta, utilizou-se de um coletor de cereal ou uma enxada. O sedimento coletado para a análise dos bentônicos foi

Tabela 1. Localização dos pontos de coleta de águas superficiais e sedimentos

\begin{tabular}{|c|c|c|c|}
\hline Pontosde Coleta & Rio & Ponto de Coleta & Localização (GPS)* \\
\hline $\mathrm{P} 1$ & Sem Nome & Montante do despejo da ETA & 23J 0210965 - UTM 7288656 \\
\hline $\mathrm{P} 2$ & Sem Nome & Jusante do despejo da ETA & 23J 0211321 - UTM 7289062 \\
\hline P3 & Ribeirão de Registro & $\begin{array}{l}\text { Montante - Contribuição do Ribeirão de } \\
\text { Registro ao Rio Sem Nome }\end{array}$ & 23J 0211555 - UTM 7289604 \\
\hline P4 & Sem Nome & $\begin{array}{l}\text { Jusante - Contribuição do Ribeirão de } \\
\text { Registro ao Rio Sem Nome }\end{array}$ & 23J 0212157 - UTM 7289417 \\
\hline P5 & Ribeira de Iguape & $\begin{array}{l}\text { Montante - Contribuição do Rio Sem Nome } \\
\text { ao Ribeira de Iguape }\end{array}$ & 23J 0211444 - UTM 7290512 \\
\hline P6 & Ribeira de Iguape & $\begin{array}{l}\text { Jusante - Contribuição do Rio Sem Nome } \\
\text { ao Ribeira de Iguape }\end{array}$ & 23J 0212148 - UTM 7289083 \\
\hline
\end{tabular}

* Global Position System 


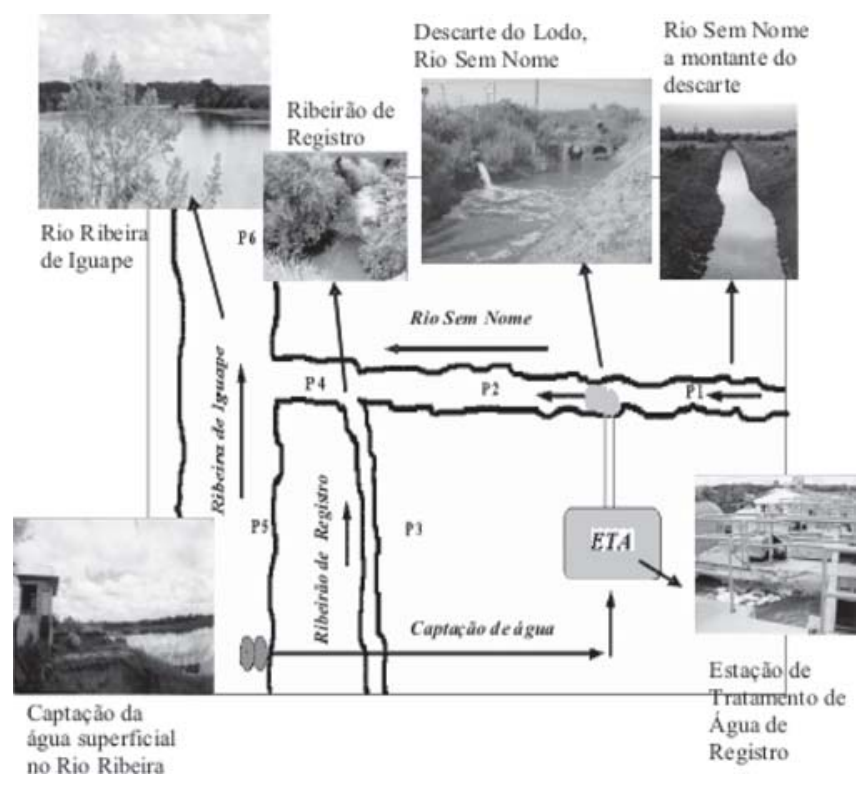

Figura 1. Localização dos pontos de coleta nos rios Sem Nome e Ribeira de Iguape, Registro, SP

devidamente lavado (peneira $250 \mu \mathrm{m}$ ), em seguida flotado em solução de cloreto de sódio. O sobrenadante e restos de substratos foram preservados em solução de formalina $4 \%$ e os organismos foram identificados em nível de família ${ }^{22,23}$.

\section{Determinação analítica}

Foram selecionados os principais parâmetros físicos, químicos e biológicos para análise das amostras de águas superficiais. As análises foram executadas em prazos máximos correspondentes a 6 meses para metais nas amostras de sedimento seco $\left(65^{\circ} \mathrm{C}\right)$ e 7 dias para os demais parâmetros nas amostras de água. Alguns parâmetros físico-químicos foram medidos no momento da coleta e na própria ETA, como pH, oxigênio dissolvido (OD) e turbidez.

As análises de sólidos totais foram realizadas nas amostras de água sem preservação, enquanto as análises de metais foram executadas em amostras preservadas (em solução de $\mathrm{HNO}_{3} 2 \%$ ) de água e amostras de sedimento no Laboratório de Análises Químicas e Ambientais do Centro de Química e Meio Ambiente (CQMA) do IPEN. A determinação dos metais e elementos traços nas amostras de águas superficiais foi realizada na fração solúvel do material coletado e comparada com a legislação federal vigente ${ }^{8}$, por meio de filtração prévia em papel de filtro de porosidade média, determinando-se os elementos por meio das técnicas de espectrometria de emissão ótica com fonte de plasma induzido (ICP-OES) Spectroflame M 120E, da Spectro Analytical Instruments e, espectrometria de absorção atômica com forno de grafita (AA), modelo Perkin Elmer Analyst $800{ }^{9}$. Todos os ácidos utilizados foram de grau analítico (Merck, Baker ou similar). As soluções padrão multi-elementares, contendo os elementos-traço utilizados (com o propósito de padronização do método) nas análises de ICPOES, foram preparadas em meio $5 \%(\mathrm{v} / \mathrm{v}) \mathrm{HNO}_{3}$, de acordo com soluções padrão de referência com certificado de pureza (Merck) com concentração certificada de $1000 \mathrm{mg} \mathrm{L}^{-1}$. As soluções padrão multi-elementares foram preparadas a partir dos analitos: alumínio $(\mathrm{Al})$, bário $(\mathrm{Ba})$, boro $(\mathrm{B})$, cádmio $(\mathrm{Cd})$, cálcio $(\mathrm{Ca})$, chumbo $(\mathrm{Pb})$, cromo $(\mathrm{Cr})$, cobalto $(\mathrm{Co})$, cobre $(\mathrm{Cu})$, estrôncio $(\mathrm{Sr})$, fósforo $(\mathrm{P})$, ferro $(\mathrm{Fe})$, magnésio $(\mathrm{Mg})$, manganês $(\mathrm{Mn})$, molibdênio $(\mathrm{Mo})$, níquel $(\mathrm{Ni})$, potássio $(\mathrm{K})$, prata $(\mathrm{Ag})$, sódio $(\mathrm{Na})$, vanádio $(\mathrm{V})$ e zinco (Zn). As calibrações foram executadas com a diluição das soluções multi-elementares para concentrações apropriadas e todos os reagentes usados foram de grau analítico.

A validação da metodologia analítica foi efetuada pela análise de material de referência certificado para análise de água e avaliação do procedimento de lixiviação em sedimentos ${ }^{24,25}$. A determinação dos metais lixiviáveis (com potencial biodisponível) nas amostras de sedimento foi realizada atravéz de lixiviação por meio de agitação mecânica por $2 \mathrm{~h}$ a $150 \mathrm{rpm}$ com um volume de $50 \mathrm{~mL}$ de solução de $\mathrm{HCl} 0,1 \mathrm{M}$, seguido de filtração em papel Whatman $\mathrm{n}^{\circ} .42$ e acondicionamento em frascos plásticos apropriados, de forma a liberar elementos em níveis de traços associados com as frações trocáveis, carbonatos, óxidos de ferro e manganês, além de matéria orgânica ${ }^{26}$.

A qualidade dos sedimentos coletados foi avaliada comparandose com os parâmetros de qualidade ambientais canadenses ${ }^{15}$, que estabelecem dois níveis de classificação: TEL ("Threshold Effect Level"), que representa concentrações abaixo das quais não são esperados efeitos adversos sobre organismos aquáticos e PEL ("Probable Effect Level"), que descreve concentrações acima das quais são esperados efeitos adversos severos sobre organismos aquáticos. Para a maior parte dos metais lixiviáveis analisados, espera-se um background de concentração que seja normal e característico de toda a área de amostragem, decorrente do solo e das rochas da região, excluindo-se contribuições de fontes antropogênicas. Os resultados obtidos foram analisados utilizando-se o programa Statistica ${ }^{27}$.

\section{RESULTADOS}

\section{Análise de águas superficiais}

Foram realizadas medidas de concentração dos elementos majoritários e em níveis de traços na fração solúvel de amostras de águas superficiais nos pontos de coleta (P1 a P6), no prazo de 24 h após o descarte de lodo. Os analitos foram escolhidos baseando-se nos resultados prévios obtidos na caracterização do lodo por Fluorescência de Raios $X^{28,29}$. Em uma primeira avaliação, verificou-se que para os elementos majoritários e alguns elementos em níveis de traços foram encontrados níveis de concentração semelhantes nos pontos de coleta P1 e P2, respectivamente a montante e jusante do Rio Sem Nome (Figuras 2 a 4).

Uma avaliação realizada bimestralmente em 50 variáveis de qualidade de recursos hídricos, em 330 pontos de amostragem em diversas regiões do estado de São Paulo pela CETESB no ano de $2004^{16}$, demonstrou que apesar de alguns parâmetros de qualidade terem apresentado não conformidades, em desacordo com o Decreto Estadual $\mathrm{N}^{\circ}$. $10.755 / 77^{12}$, muitos dos resultados encontrados estão relacionados

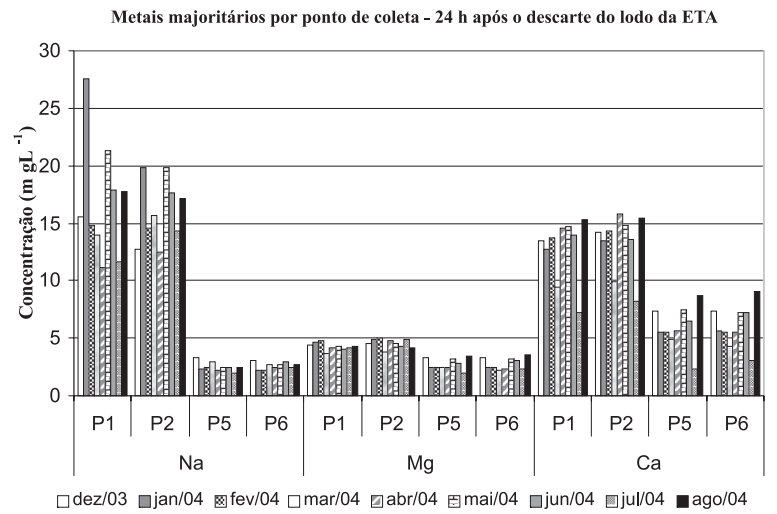

Figura 2. Elementos majoritários em amostras de águas superficiais 


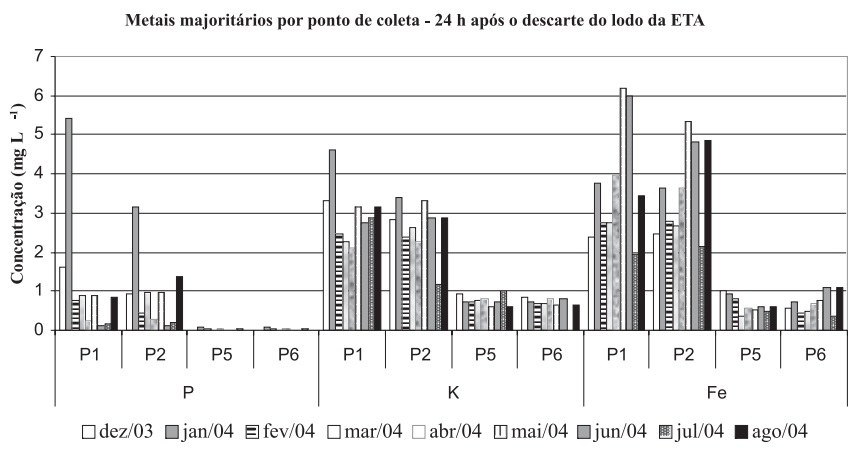

Figura 3. Elementos majoritários em amostras de águas superficiais

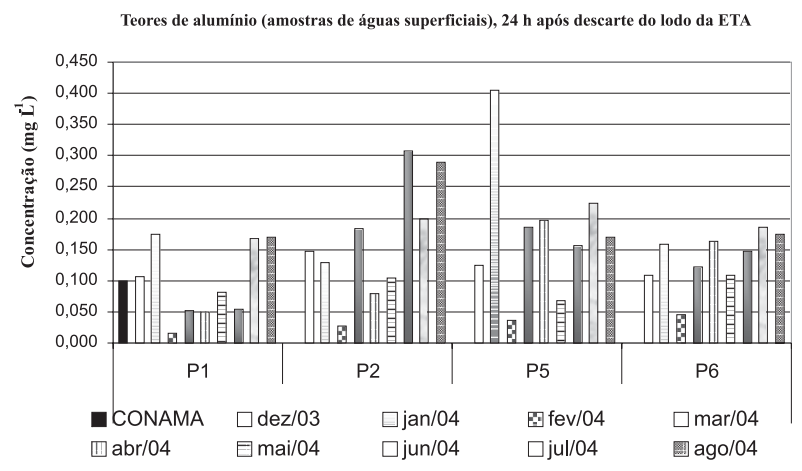

Figura 4. Teores de alumínio em amostras de águas superficiais

a fatores ambientais naturais. Algumas substâncias químicas, como alumínio, ferro e manganês, ocorrem naturalmente em quantidade significativa nos solos paulistas, incluindo a Região Metropolitana de São Paulo e, por esse motivo, parte dessas substâncias é carreada para os corpos d'água em decorrência do manejo agrícola inadequado ou das chuvas ${ }^{16}$. Na avaliação da variação espacial e temporal do Al (Figura 4) na fração solúvel das amostras de águas superficiais, pôde-se observar teores muito acima do estabelecido pela Legislação Federal ${ }^{8}$, em todos os pontos de coleta e não apenas nos pontos a jusante do descarte, mostrando que sua presença não está associada a atividades antrópicas, como o descarte do lodo da ETA. Apesar do lodo de ETA geralmente apresentar altas concentrações de $\mathrm{Al}^{30}$, a influência do seu descarte não se evidencia nas amostras de águas superficiais recolhidas $24 \mathrm{~h}$ depois do lançamento nos cursos d'água, em pontos de amostragem localizados a jusante da ETA (P2 e P6). A presença de P (encontrado nas coletas realizadas nos pontos P1 e P2) constitui-se de uma exceção, por mostrar um comprometimento da qualidade das águas do Rio Sem Nome, em decorrência de descarga irregular de esgoto por todo o percurso deste rio, conforme observado ao longo de todo o período de estudo. Quando são considerados alguns resultados obtidos para os metais tóxicos avaliados, observa-se que elementos como $\mathrm{Co}, \mathrm{Mn}, \mathrm{Ni}, \mathrm{Cu}, \mathrm{Zn}, \mathrm{Ag}$ e Cd foram encontrados em algumas coletas em níveis acima dos limites estabelecidos pelo CONAMA ${ }^{8}$. Contudo, neste caso também se constata que as concentrações máximas encontradas não podem ser consideradas como consequiência direta do descarte de lodo pela ETA, conforme verificado na comparação das medidas realizadas a montante e jusante.

A similaridade encontrada entre os níveis de concentração dos elementos avaliados, principalmente nos pontos de coleta P1 e P2, demonstra que, para os parâmetros avaliados, não há evidência direta de impacto do despejo mensal da ETA no curso d'água receptor (Rio Sem Nome). O mesmo foi observado entre os pontos P5 e P6, correspondentes a montante e jusante da contribuição do Rio Sem Nome no Rio Ribeira de Iguape, indicando uma rápida dispersão do efluente da

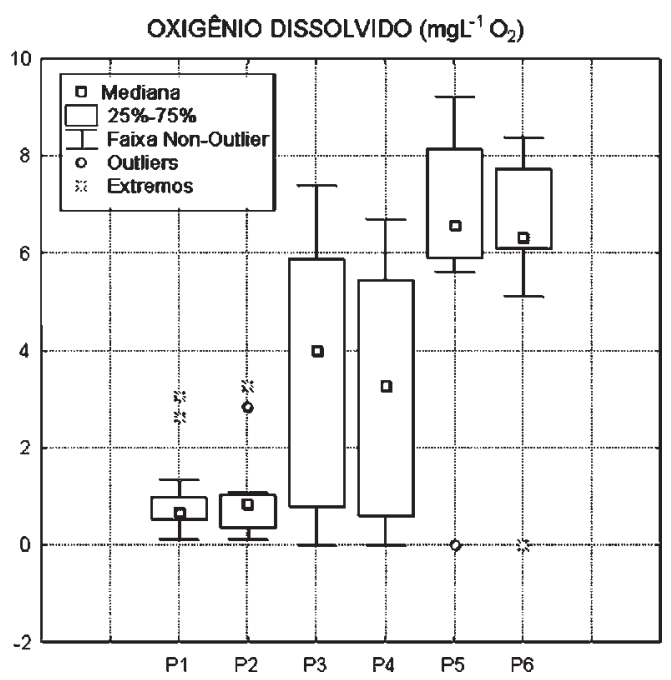

Figura 5. "Box plots" do parâmetro oxigênio dissolvido, 24 h após o descarte do lodo

ETA. A avaliação destes dois pontos de coleta demonstra que o despejo da ETA recebido pelo curso d'água receptor (Rio Sem Nome) também não compromete diretamente a qualidade das águas superficiais do rio Ribeira de Iguape ${ }^{28,29}$. Por outro lado, a diferença nos níveis de concentração dos elementos avaliados e encontrados nos pontos de coleta no Rio Sem Nome (P1 e P2) e no Rio Ribeira de Iguape (P5 e P6) evidencia também uma diferença na qualidade das águas dos rios estudados, apesar dos elementos $\mathrm{Na}, \mathrm{Mg}, \mathrm{K}$ e Ca não serem considerados como parâmetros de qualidade de água pelo CONAMA $357^{8}$. Com exceção do $\mathrm{Al}$, a maioria dos elementos analisados apresentou concentrações inferiores aos níveis estabelecidos para amostras de águas denominadas Classe $2^{8}$.

Também não foram observadas variações significativas entre as coletas realizadas no decorrer do estudo, o que demonstra haver uma rápida dispersão dos resíduos da ETA, apesar de diferenças no clima observadas no período ${ }^{31}$.

A constatação de que o despejo do lodo apresenta pouco impacto nas águas superficiais tanto em rio com pequena vazão (Rio Sem Nome), quanto em um rio volumoso (Ribeira de Iguape), sugere que o efeito do lodo da ETA possa ser maior no sedimento e na biota. Por outro lado, o uso de sulfato de alumínio como agente coagulante pela ETA não apresentou influência nos parâmetros naturais de qualidade das águas nos pontos de coleta a jusante do despejo. Foram analisados alguns parâmetros físico-químicos nas amostras de água para avaliação da influência do despejo dos resíduos da ETA, como níveis de oxigênio dissolvido, turbidez, alcalinidade, dureza, sólidos totais, sólidos totais fixos, sólidos voláteis e $\mathrm{pH}$, durante o período de coleta. A Figura 5 mostra o "box plots" obtido para o parâmetro oxigênio dissolvido para todo o período de coleta, onde (da mesma forma que para os demais parâmetros, como turbidez, pH, sólidos totais e metais) percebem-se características similares entre os pontos de coleta P1 e P2, demonstrando nenhuma influência do descarte do lodo da ETA no local de coleta no ponto de coleta P2, a jusante do próprio despejo. A similaridade também observada entre P5 e P6 mostra que, para os parâmetros medidos, não se observa impacto do descarte do lodo no deságüe do Rio Sem Nome no Rio Ribeira de Iguape. Por outro lado, a semelhança dos gráficos entre os pontos $\mathrm{P} 3$ e P4 aponta que o Ribeirão de Registro não causa qualquer alteração química relevante quando deságua no Rio Sem Nome ${ }^{32}$.

Os mesmos parâmetros utilizados para avaliação por box-plots foram submetidos à análise estatística multivariada por dendogramas ${ }^{27}$, onde cada parâmetro físico-químico é tratado como uma variável independente (Figura 6). Apesar da aplicação de dendogramas apontar 
para a mesma conclusão obtida quando se utiliza o método de boxplots, seu uso possibilita evidenciar a distribuição geográfica dos cursos d'água no em torno da ETA de Registro, quando se relaciona a similaridade observada entre os pontos de coleta.

De acordo com os resultados apresentados na Figura 6 e conforme observado no período do estudo, os pontos de coleta P1 e P2 apresentam-se agrupados, pois são localizados no mesmo curso d'água (Rio Sem Nome); o mesmo ocorre com os pontos P5 e P6, que se encontram no Rio Ribeira de Iguape. Os pontos P3 e P4 mostram a influência do deságüe do Ribeirão de Registro no Rio Sem Nome e mesmo no Ribeira de Iguape. O gráfico demonstra também que os parâmetros utilizados são adequados para caracterizar e associar quimicamente cursos d'água diferentes. Os resultados referentes aos meses de coleta realizados apresentaram a mesma distribuição dos pontos de coletas em períodos de um dia antes e um dia depois da descarga do lodo da ETA $^{32}$.

\section{Análise de sedimentos}

As Tabelas 2 e 3 mostram os resultados obtidos para o extrato lixiviado do sedimento coletado nos rios do em torno da ETA, em amostragens realizadas $24 \mathrm{~h}$ após o descarte do lodo. A avaliação restringiu-se aos períodos de chuva (Dezembro/2003 a Janeiro/2004) e estiagem (Junho a Agosto/2004), comparando-se os resultados obtidos aos valores de referência TEL e PEL, estabelecidos para amostras de sedimento.

Os parâmetros adotados neste estudo são geralmente utilizados para avaliação do potencial efeito biológico causado pela remoção da fração

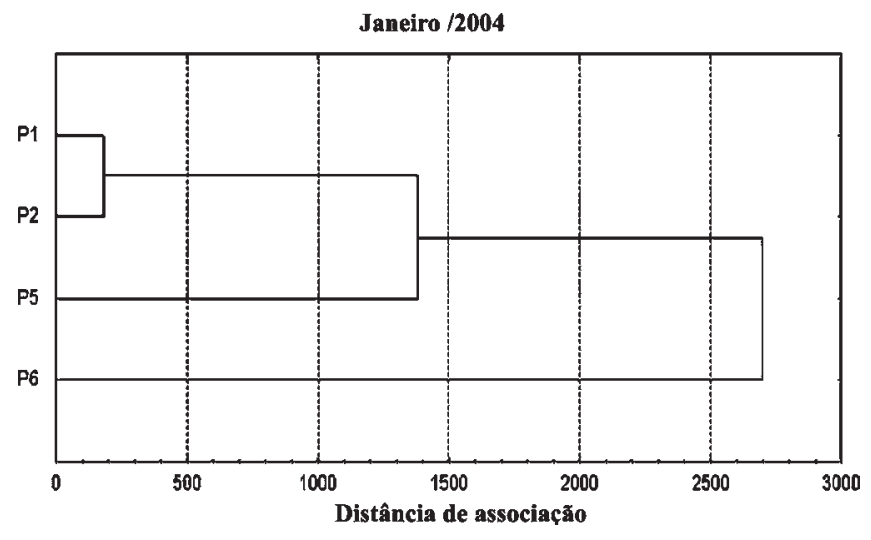

Figura 6. Dendograma representando diferentes cursos d'água no período de coleta de janeiro de 2004, 24 h após a descarga do lodo de ETA

biologicamente lixiviável dos metais, por meio de digestão ácida moderada, e não da fração residual dos metais (ligados à estrutura cristalina do sedimento), que seria obtida por digestão utilizando-se ácido fluorídrico ${ }^{9,15}$. Com exceção do alumínio, os elementos determinados nas amostras de sedimentos não evidenciaram um impacto do despejo, especialmente aquelas coletadas no ponto $\mathrm{P} 2$, pois não se observou um aumento nos níveis de concentração em relação aos resultados obtidos no ponto de coleta localizado a montante do despejo (P1). Alguns elementos, como $\mathrm{Mg}, \mathrm{Cu}$ e $\mathrm{Pb}$, apresentaram valores acima dos estabelecidos $^{15}$, porém sem associação direta com o despejo do lodo, como os

Tabela 2. Estatística descritiva para as concentrações elementos traços na fração lixiviável de amostras de sedimento $\left(\mathrm{mg} \mathrm{kg}^{-1}\right)$, para o período de chuva (Dezembro/2003 a Fevereiro/2004)

\begin{tabular}{|c|c|c|c|c|c|c|c|c|c|c|c|c|c|c|c|c|c|c|}
\hline & & $\mathrm{Na}$ & $\mathrm{Mg}$ & $\mathrm{P}$ & $\mathrm{K}$ & $\mathrm{Ca}$ & $\mathrm{Fe}$ & $\mathrm{Ba}$ & Co & $\mathrm{Al}$ & V & $\mathrm{Cr}$ & Mn & $\mathrm{Ni}$ & $\mathrm{Cu}$ & $\mathrm{Zn}$ & $\mathrm{Cd}$ & $\mathrm{Pb}$ \\
\hline \multirow{3}{*}{ P1 } & Média & 15,4 & 1.340 & 131 & 63,5 & 8.431 & 3.692 & 143 & 7,71 & 1.185 & 11,6 & 1,79 & 85,9 & 2,77 & 12,1 & 71,0 & 0,20 & 14,1 \\
\hline & Mediana & 21,8 & 1.245 & 125 & 66,4 & 6.073 & 4.763 & 162 & 8,42 & 1.258 & 11,7 & 2,14 & 80,2 & 2,06 & 15,2 & 75,0 & 0,15 & 17,1 \\
\hline & Mínimo & 0,53 & 453 & 58,9 & 25,9 & 3.778 & 1.150 & 47,1 & 3,12 & 414 & 6,87 & 0,65 & 40,4 & 1,10 & 3,9 & 24,1 & 0,07 & 4,4 \\
\hline \multirow{4}{*}{ P2 } & Média & 11,3 & 344 & 90,4 & 41,9 & 1.557 & 3.840 & 141 & 8,33 & 3.250 & 18,6 & 1,73 & 68,9 & 1,50 & 12,3 & 57,3 & 0,15 & 15,6 \\
\hline & Mediana & 9,91 & 359 & 87,3 & 37,9 & 1.670 & 3.823 & 141 & 8,47 & 3.009 & 18,6 & 1,83 & 67,4 & 1,55 & 12,2 & 59,9 & 0,11 & 16,1 \\
\hline & Máximo & 23,4 & 431 & 98,8 & 49,8 & 2.065 & 4.201 & 147 & 8,68 & 3.858 & 21,3 & 2,03 & 82,6 & 1,83 & 14,1 & 67,0 & 0,25 & 18,3 \\
\hline & Mínimo & 0,53 & 242 & 85,1 & 37,9 & 937 & 3.496 & 134 & 7,84 & 2.883 & 16 & 1,34 & 56,8 & 1,13 & 10,7 & 45,1 & 0,10 & 12,3 \\
\hline \multirow{3}{*}{ P3 } & Média & 14,7 & 519 & 33,8 & 45,3 & 1.892 & 4.233 & 169 & 9,16 & 1.289 & 15 & 1,28 & 102 & 2,60 & 25,8 & 87,0 & 0,20 & 25,0 \\
\hline & Mediana & 4,4 & 583 & 26,7 & 36,2 & 2.167 & 3.942 & 187 & 9,41 & 1.197 & 16,7 & 1,43 & 98,3 & 2,61 & 24,4 & 75,1 & 0,21 & 25,7 \\
\hline & Máximo & 39,1 & 655 & 49,2 & 74,8 & 2.605 & 6.614 & 214 & 13,3 & 2.143 & 19,5 & 1,74 & 148 & 3,67 & 39,5 & 122,0 & 0,30 & 29,6 \\
\hline \multirow{4}{*}{ P4 } & Média & 4,52 & 288 & 33,2 & 56,8 & 1.233 & 3.764 & 216 & 9,42 & 1.569 & 13,5 & 0,99 & 162 & 1,81 & 12,0 & 36,6 & 0,11 & 28,1 \\
\hline & Mediana & 5,06 & 336 & 40,1 & 47,8 & 1.024 & 3.542 & 212 & 9,41 & 1.830 & 13,8 & 1,05 & 130 & 1,72 & 10,4 & 39,7 & 0,10 & 21,4 \\
\hline & Máximo & 7,98 & 389 & 45,8 & 89,9 & 1.807 & 5.434 & 282 & 11,8 & 2.131 & 16 & 1,27 & 249 & 2,23 & 16,0 & 51,6 & 0,17 & 49,6 \\
\hline & Mínimo & 0,53 & 138 & 13,7 & 32,8 & 868 & 2.317 & 154 & 7,04 & 747 & 10,6 & 0,65 & 108 & 1,49 & 9,5 & 18,6 & 0,07 & 13,4 \\
\hline \multirow{4}{*}{ P5 } & Média & 0,53 & 525 & 18,3 & 45,4 & 1.837 & 3.830 & 295 & 11,1 & 875 & 13,7 & 1,11 & 667 & 2,31 & 13,5 & 33,3 & 0,12 & 43,8 \\
\hline & Mediana & 0,53 & 461 & 17,2 & 48,3 & 1.888 & 4.095 & 314 & 11,9 & 826 & 13,8 & 1,07 & 681 & 2,07 & 13,1 & 32,0 & 0,12 & 48,5 \\
\hline & Máximo & 0,53 & 660 & 21,3 & 53,4 & 1.958 & 4.313 & 328 & 12,7 & 1106 & 17 & 1,28 & 774 & 2,93 & 15,7 & 38,2 & 0,15 & 49,8 \\
\hline & Mínimo & 0,53 & 455 & 16,3 & 34,4 & 1.665 & 3.081 & 243 & 8,75 & 695 & 10,4 & 0,98 & 546 & 1,94 & 11,7 & 29,6 & 0,10 & 33,1 \\
\hline \multirow{4}{*}{ P6 } & Média & 0,53 & 419 & 7,7 & 29,2 & 1.167 & 1.345 & 226 & 5,2 & 638 & 12 & 0,68 & 246 & 1,69 & 10,2 & 18,4 & 0,12 & 21,2 \\
\hline & Mediana & 0,53 & 421 & 8,77 & 27,6 & 1.139 & 1.410 & 213 & 5,43 & 674 & 10 & 0,65 & 302 & 1,38 & 10,7 & 18,3 & 0,10 & 19,9 \\
\hline & Máximo & 0,53 & 450 & 9,13 & 43,1 & 1.259 & 1.768 & 255 & 5,8 & 698 & 17 & 0,75 & 313 & 2,37 & 13,4 & 20,2 & 0,16 & 27,3 \\
\hline & Mínimo & 0,53 & 387 & 5,21 & 16,9 & 1.103 & 858 & 211 & 4,53 & 544 & 8,98 & 0,65 & 124 & 1,33 & 6,5 & 16,7 & 0,10 & 16,3 \\
\hline
\end{tabular}


Tabela 3. Estatística descritiva para as concentrações de elementos traços na fração lixiviável de amostras de sedimento $\left(\mathrm{mg} \mathrm{kg}^{-1}\right)$, para o período de estiagem (Junho/2004 a Agosto/2004)

\begin{tabular}{|c|c|c|c|c|c|c|c|c|c|c|c|c|c|c|c|c|c|c|}
\hline & & $\mathrm{Na}$ & $\mathrm{Mg}$ & $\mathrm{P}$ & K & $\mathrm{Ca}$ & $\mathrm{Fe}$ & $\mathrm{Ba}$ & Co & $\mathrm{Al}$ & V & $\mathrm{Cr}$ & $\mathrm{Mn}$ & $\mathrm{Ni}$ & $\mathrm{Cu}$ & $\mathrm{Zn}$ & $\mathrm{Cd}$ & $\mathrm{Pb}$ \\
\hline \multirow{4}{*}{ P1 } & Média & 37,0 & 1.220 & 106 & 88,9 & 5.583 & 4.958 & 96,2 & 8,69 & 1.505 & 11,6 & 3,14 & 71,5 & 3,41 & 13,7 & 73,5 & 0,14 & 13,4 \\
\hline & Mediana & 27,2 & 1.073 & 122 & 109 & 4.641 & 5.003 & 111 & 12,3 & 1.623 & 12,8 & 3,52 & 63,3 & 3,37 & 14,7 & 81,4 & 0,21 & 16,0 \\
\hline & Máximo & 71,7 & 2.185 & 165 & 132 & 11.100 & 7.728 & 152 & 13,0 & 2.363 & 17,2 & 4,72 & 126 & 3,95 & 21,4 & 119 & 0,23 & 17,2 \\
\hline & Mínimo & 12,1 & 402 & 29,6 & 25,8 & 1.007 & 2.143 & 25,6 & 0,78 & 530 & 4,83 & 1,17 & 25,1 & 2,90 & 4,88 & 20,2 & 0,18 & 6,9 \\
\hline \multirow{4}{*}{ P2 } & Média & 39,2 & 442 & 137 & 66,4 & 2.616 & 4.706 & 86,7 & 9,59 & 5.464 & 15,2 & 3,49 & 126 & 1,63 & 12,3 & 44,6 & * & 17,0 \\
\hline & Mediana & 38,4 & 433 & 167 & 73,9 & 2.490 & 4.110 & 81,1 & 10,7 & 5.700 & 15,8 & 2,98 & 120 & 1,72 & 12 & 48,4 & 0,13 & 18,0 \\
\hline & Máximo & 63,1 & 489 & 167 & 83,4 & 3.078 & 5.913 & 123 & 13,2 & 7.403 & 19,6 & 5,23 & 166 & 1,80 & 14,4 & 49,1 & 0,13 & 18,4 \\
\hline & Mínimo & 16,2 & 404 & 76,6 & 41,8 & 2.280 & 4.095 & 55,9 & 4,87 & 3.290 & 10,3 & 2,25 & 91,2 & 1,38 & 10,4 & 36,4 & 0,13 & 14,7 \\
\hline \multirow{4}{*}{ P3 } & Média & 37,6 & 467 & 71,4 & 54,9 & 1.504 & 4.077 & 74,8 & 8,03 & 983 & 15,0 & 1,50 & 148 & 2,43 & 29 & 79,7 & 0,10 & 19,8 \\
\hline & Mediana & 51,8 & 418 & 40,8 & 43,0 & 1.342 & 3.820 & 60,4 & 9,53 & 948 & 12,9 & 1,71 & 164 & 1,85 & 31,9 & 87,6 & 0,15 & 23,5 \\
\hline & Máximo & 54,1 & 735 & 142 & 89,1 & 2.380 & 4.943 & 104 & 12,5 & 1.515 & 23,1 & 1,90 & 180 & 3,85 & 47,3 & 131 & 0,18 & 25,4 \\
\hline & Mínimo & 7,03 & 249 & 31,5 & 32,6 & 790 & 3.468 & 59,9 & 2,05 & 487 & 8,97 & 0,88 & 101 & 1,60 & 7,95 & 20,6 & 0,12 & 10,6 \\
\hline \multirow{4}{*}{ P4 } & Média & 13,4 & 385 & 51,7 & 77,9 & 2.087 & 4.669 & 87,6 & 8,30 & 1.203 & 10,1 & 1,67 & 192 & 1,80 & 11,3 & 52,3 & * & 41,4 \\
\hline & Mediana & 13,3 & 329 & 47,2 & 49,2 & 1.091 & 5.820 & 92,6 & 6,52 & 1.279 & 10,4 & 1,13 & 175 & 1,80 & 10,5 & 41,9 & 0,20 & 27,1 \\
\hline & Máximo & 14,0 & 602 & 65,1 & 138 & 4.145 & 6.032 & 95 & 12,1 & 1.434 & 11,1 & 2,95 & 269 & 1,87 & 14,1 & 76,2 & 0,20 & 84,4 \\
\hline & Mínimo & 12,8 & 223 & 42,7 & 46,6 & 1.024 & 2.155 & 75,1 & 6,18 & 896 & 8,80 & 0,93 & 132 & 1,73 & 9,27 & 38,9 & 0,20 & 12,6 \\
\hline \multirow{4}{*}{ P5 } & Média & * & * & * & $*$ & * & * & * & * & * & $*$ & * & * & * & * & $*$ & * & $*$ \\
\hline & Mediana & 9,50 & 667 & 19,4 & 54,0 & 1.577 & 3.558 & 157 & 7,00 & 897 & 8,05 & 1,24 & 714 & 2,44 & 11,8 & 34,5 & 0,13 & 37,9 \\
\hline & Máximo & 13,2 & 876 & 25,8 & 72,9 & 2.032 & 4.120 & 192 & 9,38 & 1.090 & 9,22 & 1,45 & 920 & 2,85 & 13,9 & 40,4 & 0,13 & 42,6 \\
\hline & Mínimo & 5,80 & 458 & 13,1 & 35,0 & 1.122 & 2.995 & 122 & 4,62 & 704 & 6,88 & 1,02 & 509 & 2,02 & 9,62 & 28,6 & 0,13 & 33,1 \\
\hline \multirow{4}{*}{ P6 } & Média & 10,2 & 707 & 22,5 & 59,9 & 2.005 & 4.446 & 163 & 11,7 & 1.046 & 10,7 & 1,81 & 875 & 6,04 & 14,3 & 44,9 & 0,13 & 45,9 \\
\hline & Mediana & 9,75 & 674 & 25,6 & 55,9 & 2.030 & 5.168 & 188 & 11,6 & 1.111 & 11,0 & 1,67 & 924 & 3,08 & 16,1 & 48,8 & 0,12 & 45,4 \\
\hline & Máximo & 17,5 & 918 & 26,9 & 81,0 & 2.332 & 5.978 & 214 & 12,0 & 1.223 & 12,6 & 2,13 & 1.253 & 13,2 & 16,8 & 51,6 & 0,15 & 48,5 \\
\hline & Mínimo & 3,40 & 528 & 15,1 & 42,7 & 1.652 & 2.192 & 87,7 & 11,4 & 805 & 8,38 & 1,63 & 448 & 1,83 & 10,1 & 34,2 & 0,12 & 43,7 \\
\hline
\end{tabular}

valores observados no ponto P5 localizado próximo do ponto de captação da ETA, no Rio Ribeira de Iguape, indicando que os valores obtidos são de origem natural. No entanto, é nítido o incremento nos níveis detectados de $\mathrm{Al}$ no ponto $\mathrm{P} 2$ em relação ao ponto $\mathrm{P} 1$, em praticamente todo o período de descarte avaliado. O ponto P2 também apresentou concentrações de $\mathrm{Al}$ superiores a todos os outros pontos de coleta avaliados, comprovando que os níveis detectados são oriundos de atividades antrópicas. Quando são comparadas as médias dos valores obtidos para $\mathrm{Al}$ em amostras recolhidas nos períodos de chuva e estiagem no ponto de coleta $P 1$, percebe-se que os valores são relativamente próximos (1185 e $1505 \mathrm{mg} \mathrm{kg}^{-1}$, respectivamente), indicando um background natural, com pouca variação ao longo do ciclo hídrico. Por outro lado, avaliando-se as médias obtidas para $\mathrm{Al}$ no ponto $\mathrm{P} 2$ em relação a $\mathrm{P} 1$, percebeuse um aumento nas concentrações medidas tanto no período de estiagem (5464 mg kg-1), tanto no período de chuvas $\left(3250 \mathrm{mg} \mathrm{kg}^{-1}\right)^{28}$.

Relacionando-se as concentrações de $\mathrm{Al}$ obtidas nos dois pontos com a média mensal da quantidade de sulfato de alumínio adicionado como coagulante pela ETA de Registro, observa-se o potencial acumulador do lodo de ETA próximo ao local do despejo. Ainda que quantidades maiores do coagulante sejam adicionadas para tratamento da água bruta da ETA no período de chuva (dezembro/2003 a fevereiro/2004), especialmente em função do aumento da turbidez da água de captação, amostras de sedimento recolhidas no período de estiagem em P2 apresentaram maiores níveis de concentração de $\mathrm{Al}$, mostrando que o índice pluviométrico observado durante um ciclo hídrico é fator importante na dispersão do resíduo descartado no corpo d'água receptor.

Índices pluviométricos menores, como o verificado em agosto de 2004, podem contribuir para um menor arraste do lodo depositado e, portanto, para a detecção de maiores níveis de $\mathrm{Al}$ no sedimento do rio, mesmo quando a quantidade do coagulante adicionado seja equivalente a menos da metade da quantidade adicionada, considerando-se a média para o mês de dezembro de 2003. Portanto, os resultados obtidos indicam a presença de $\mathrm{Al}$ no ponto de amostragem localizado próximo ao despejo do lodo pela ETA de Registro. Apesar da concentração média verificada para este elemento nas amostras de sedimento apresentar valores inferiores ao estabelecido de $58030 \mathrm{mg} \mathrm{kg}^{-1}$ pelo valor-guia de PEL, a diferença de $1000 \mathrm{mg} \mathrm{kg}^{-1}$, observada entre os níveis de background natural e do detectado em função do descarte do lodo, representa por si só a capacidade potencial de deposição e contaminação do lodo da ETA. Quando se consideram os prováveis efeitos de toxicidade deste elemento ${ }^{1}$, torna-se preocupante o incremento dos níveis de contaminação de $\mathrm{Al}$ no meio ambiente, em função da projeção do descarte contínuo dos rejeitos da $\mathrm{ETA}^{32}$.

\section{Análise dos organismos bentônicos}

A influência do lançamento do lodo da ETA também foi avaliada por meio da macrofauna bentônica analisada. As análises foram realizadas pelos laboratórios do Departamento de Saúde Ambiental, Faculdade de Saúde Pública da USP. Foram realizadas 6 amostragens nos pontos de coleta (P1 a P6) durante um período de 3 meses, onde a cada mês realizaram-se 2 coletas, uma anterior e outra posterior ao descarte de lodo pela ETA. Para cada ponto de coleta foram realizadas coletas idênticas para as análises qualitativas e quantitativas dos bentônicos, recolhendo-se aproximadamente $500 \mathrm{~g}$ de sedimento de fundo.

As análises quantitativas foram realizadas com exame microscópio 
Tabela 4. Composição da comunidade bentônica nas estações de amostragem, em amostras de sedimentos

\begin{tabular}{|c|c|c|c|c|c|c|}
\hline \multirow[t]{2}{*}{ Família } & \multicolumn{6}{|c|}{ Identificação dos pontos de amostragem } \\
\hline & $\mathrm{P} 1$ & $\mathrm{P} 2$ & P3 & $\mathrm{P} 4$ & P5 & P6 \\
\hline *Mollusca-Gastropoda & + & - & + & + & - & - \\
\hline Mollusca-Pelecypoda & + & - & - & - & - & - \\
\hline Insecta-Diptera-Chironomidae & + & + & - & + & + & + \\
\hline Insecta-Diptera-Ceratopogonidae & - & - & - & - & - & + \\
\hline Insecta-Ephemeroptera & - & - & - & - & + & + \\
\hline Annelida-Oligochaeta-Tubificidae & + & - & - & + & + & + \\
\hline Annelida-Hirudinea & + & + & - & - & - & - \\
\hline Total & 5 & 2 & 1 & 3 & 3 & 4 \\
\hline
\end{tabular}

(+) Presença; (-) Ausência

estereoscópico, em relação aos organismos encontrados e sua presença ou ausência em cada ponto de amostragem, e se encontram apresentadas na Tabela 4. A densidade numérica dos microorganismos também foi relacionada. O ponto 1 apresentou uma concentração elevada da família Chironomidae no mês de setembro (> 800 organismos $\left.\mathrm{m}^{-3}\right)$. Este resultado pode ser explicado em razão da maior quantidade de alimentos (matéria orgânica) advinda de descargas de esgoto doméstico observadas no local ${ }^{33}$. Hirabayashi et al. $^{34}$ relataram que pode ocorrer correlação entre a eutrofização e a dominância da família Chironomidae. Por outro lado, os pontos 2, 3 e 4 apresentaram menor diversidade e densidade numérica de organismos. Apesar de receberem contribuição direta do ponto 1 e da própria ETA, foi observado nos pontos 2 e 4 um substrato que apresentou uma fauna bentônica pouco influenciada pelos despejos de esgotos observados em P1 e, principalmente, pelo despejo do lodo da $\mathrm{ETA}^{22}$. Em relação aos pontos de coleta anteriores, os pontos 5 e 6 apresentaram maior diversidade com alguns organismos considerados de águas limpas, como por ex., a família Ephemeroptera, possivelmente porque ambos os pontos estão localizados no Rio Ribeira de Iguape, que é um rio classificado como Classe $2^{20}$. Deve ser ressaltado que apesar do ponto 6 estar localizado após o deságüe do Rio Sem Nome no Rio Ribeira de Iguape, não foi observada nenhuma diferença significativa na macrofauna bentônica em relação a P5. Em razão da semelhança observada entre estes pontos, pode-se admitir a ocorrência de um processo de autodepuração natural ao longo do próprio Rio Sem Nome, em razão do impacto pouco significativo do descarte do lodo da ETA no corpo d'água receptor. Ao se considerar a macrofauna bentônica em sua totalidade, evidenciou-se a presença dos grupos OligochaetaTubificidae e Diptera-Chironomidae entre os seis pontos de amostragem, durante o período de estudo. No entanto, apesar dos grupos Chironomidae (Diptera) e Annelida-Oligochaeta (vermes segmentados) serem considerados indicadores de água poluída ${ }^{22,35}$, são também organismos que se alimentam de material em decomposição e que apresentam preferência por sedimentos moles ${ }^{36}$, característicos da região.

\section{CONCLUSÕES}

Os resíduos dispostos mensalmente pela ETA de Registro nos cursos d'água no seu em torno não demonstraram riscos imediatos quanto à possibilidade de alteração da qualidade das amostras de água superficial, quando comparados com valores estabelecidos pelo CONAMA 357, uma vez que cada curso d'água analisado apresentou as mesmas características físico-químicas comparando-se coletas de águas superficiais realizadas a montante e jusante da descarga do lodo da ETA.

O índice pluviométrico médio observado no período chuvoso mostrou-se fundamental na dispersão do lodo descartado, mesmo com maior adição de coagulante pela ETA nas etapas de tratamento, especialmente porque os resultados apresentados foram baseados em análises em um pequeno curso d'água (Rio Sem Nome), cujo volume de vazão pode se apresentar mais suscetível a alterações climáticas. A análise dos dados obtidos em amostras de águas superficiais pelo uso de dendogramas mostrou que os parâmetros utilizados foram adequados para caracterizar os locais de diferentes amostragens, em função da similaridade química evidenciada por pontos de coleta situados em um mesmo curso d'água.

A análise de cluster demonstrou praticamente a mesma distribuição dos pontos de coletas ao longo de todo o período de estudo, confirmando a ausência de quaisquer contaminações aparentes do despejo da ETA, de acordo com as condições e os parâmetros físicoquímicos utilizados. Em relação aos organismos bentônicos, podese admitir que apesar dos dados coletados não se apresentarem definitivamente conclusivos em relação a um possível efeito do lançamento do lodo da ETA sobre estes, existe uma indicação de que os grupos observados como típicos de ambiente com poluição orgânica e do próprio tipo de sedimento característico da região (mole e lodoso) não foram diretamente afetados pelo despejo do lodo da ETA.

O descarte dos resíduos provenientes da Estação de Tratamento de Água de Registro pode, no entanto, impactar o meio ambiente local em função dos níveis de $\mathrm{Al}$ encontrados em amostras de sedimento lixiviado no ponto de coleta logo após o descarte do lodo da ETA. Apesar dos níveis encontrados para este elemento serem inferiores aos níveis de referência PEL utilizados, deve-se considerar os efeitos a longo prazo do depósito dos resíduos da ETA no meio ambiente local. Embora os resultados obtidos não demonstrem uma contaminação direta, programas que visem enquadrar os lançamentos de lodo de ETA às legislações vigentes devem ser implantados para colaborar com a proteção dos cursos d'água.

\section{MATERIAL SUPLEMEMENTAR}

Em http://quimicanova.sbq.org.br podem ser encontradas Tabelas e Figuras adicionais, em forma de arquivo PDF, com acesso gratuito.

\section{AGRADECIMENTOS}

À Fundação Amparo à Pesquisa do Estado de São Paulo (FAPESP) e ao Conselho Nacional de Pesquisa e Desenvolvimento $(\mathrm{CNPq})$ pelo apoio financeiro, e à SABESP pelo apoio nas coletas e no desenvolvimento do trabalho. Os autores também agradecem às valiosas informações concedidas por G. da Silva, I. Villanova e J. C. de Morais, da ETA de Registro.

\section{REFERÊNCIAS}

1. Reali, M. A. P.; Projeto PROSAB - Noções gerais de tratamento e disposição final de estações de tratamento de água, ABES, Rio de Janeiro: 1999.

2. Instituto Brasileiro de Geografia e Estatística; Atlas de Saneamento - Pesquisa Nacional de Saneamento Básico 2000 (PNSB), IBGE: Brasília, 2004. 
3. Cordeiro, J. S.; Tese de Doutorado, Universidade Federal de São Carlos, Brasil, 1993.

4. Lester, J. N.; Heavy Metals in Wastewater and Sludge Treatment Process, CRC Press: Boca Raton, 1987.

5. Hoppen, C.; Portella, K. F.; Joukoski, A.; Trindade, E. M.; Andreóli, C. V.; Quim. Nova 2006, 29, 79.

6. Hoppen, C.; Portella, K. F.; Joukoski, A.; Cerâmica 2005, 51, 85.

7. Ferreira Filho, S. S.; Marchetto, M.; Engenharia Sanitária e Ambiental, Editora ABES - Associação Brasileira d Engenharia Sanitária: Rio de Janeiro, 2006, vol. 11, p. 7-15.

8. Resolução Conama n ${ }^{\circ}$ 357; Diário Oficial da União, 17 de março de 2005.

9. Cotrim, M. E. B.; Tese de Doutorado, IPEN, Brasil, 2006

10. Departamento de Água e Energia Elétrica; Bacia do rio Ribeira de Iguape - Caracterização dos usos e das disponibilidades hídricas, DAEE: São Paulo, 1984.

11. Hogan, D. J.; Carmo, R. L.; Alves, H. P. F.; Rodrigues, I. A.; Ambiente \& Sociedade 1998, vol. 3, p. 151.

12. Constituição do Estado de São Paulo; Assembléia Legislativa do Estado de São Paulo, 1989.

13. Companhia de Tecnologia e Saneamento Ambiental; Relatório de Qualidade de Águas Interiores do Estado de São Paulo 1999, CETESB: São Paulo, 2000.

14. Companhia de Tecnologia e Saneamento Ambiental; Relatório de Qualidade de Águas Interiores do Estado de São Paulo 2000, CETESB: São Paulo, 2001.

15. Canadian Council of Ministers of the Environment; Canadian Environmental Quality Guidelines, Environment Canada: Quebec, 1999.

16. Companhia de Tecnologia e Saneamento Ambiental; Relatório de Qualidade de Águas Interiores do Estado de São Paulo 2004, São Paulo, 2005.

17. Marques, M. N.; Tese de Doutorado, IPEN, Brasil, 2005.

18. Companhia de Saneamento Básico do Estado de São Paulo; Tratamento e Disposição Final do Lodo de Estação de Tratamento de Água, SABESP: São Paulo, 2003. (Relatório interno).

19. Salomons, W.; Stiglini, W. M.; Biogeodynmics of Pollutants in Soils and Sediments - Risk Assesment of Delayed and Non-Linear Reponses, Springer - Verlag Berlin Heidelberg, 1995.
20. Companhia de Tecnologia e Saneamento Ambiental; Relatório de Qualidade de Águas Interiores do Estado de São Paulo, CETESB: São Paulo, 1991.

21. APHA, AWWA, WEF; Standard Methods for the Examination of Water and Wastewater, 20 ${ }^{\text {th }}$ ed., American Public Heath Association: Washington, 1998.

22. Rocha, S. M.; Dissertação de Mestrado, Universidade de São Paulo, Brasil, 1999.

23. Brandimarte, A. L.; Anaya, A.; A.; Verhandlung Internationale Vereingung de Limnologie 1998, 26, 2358.

24. Cotrim, M. E. B.; Furusawa, H. A.; Dantas, S. K.; Gelatti, M. J. G.; Beltrame Filho, O.; Bana, B.; Pires, M. A. F.; Caracterização de sedimentos ativos de drenagem em áreas de captação, AESABESP: São Paulo, 2004.

25. Cotrim, M. E. B.; Dantas, E. K.; Filho, O. B.; Hiroi, J.; Pires, M. A. F.; Qualidade da água subterrânea utilizada para abastecimento público no Vale do Ribeira - SP, ABES: Campo Grande, 2005.

26. Gatti, L. V.; Tese de Doutorado, Universidade Federal de São Carlos, Brasil, 1997.

27. Statsoft Incorporation; Statistica and Statistica Industrial System, Tulsa: USA, 1998.

28. Reis, E. L. T.; Contrim, M.; Beltrame, O.; Pinto, O.; Souza, A.; Amalfi, P.; Pires, M. A. F.; Caracterização dos Resíduos Gerados em sistemas de Tratamento de Água, AESABESP: São Paulo, 2004.

29. Reis, E. L. T.; Cotrim, M. E.; Filho, O. B.; Badiru, A. I., Pires, M. A. F.; Water Supply, IWA Publishing 2005, 4, 139.

30. Dharmappa, H. B.; Hagare, P.; Water Sci. and Technol. 1997, 35, 45.

31. http://www.iac.sp.gov.br/Ciiagro, acessada em Outubro 2004.

32. Reis, E. L. T.; Tese de Doutorado, IPEN, Brasil, 2006.

33. Joasson, P. M.; Proceedings of the Symposium of the National Academy of Science; EUA, 1969.

34. Hirabayashi, K.; Yoshizawa, K.; Yoshida, N.; Kazama, F.; Limnology 2004, 5, 47.

35. Brinkhurst, R. O.; Cook, G. G.; Pollution Ecology of Freshwater Invertebrates, Academic Press: New York, 1974.

36. Pennak, R. W.; Freshwater Invertebrates of United States, Ronald Press Comp: New York, 1953. 


\section{IDENTIFICAÇÃO DA INFLUÊNCIA DO DESCARTE DE LODO DE ESTAÇÕES DE TRATAMENTO DE ÁGUA}

Edson Luís Tocaia dos Reis, Marycel Elena Barbosa Cotrim, Cláudio Rodrigues e Maria Aparecida Faustino Pires* Instituto de Pesquisas Energéticas e Nucleares, CP 11049, 05422-970 São Paulo - SP Brasil

\section{Osvaldo Beltrame Filho}

Setor de Controle Sanitário, Companhia Saneamento Básico do Estado de São Paulo, Rua Joaquim M. Alves, 1002, 11900-000 Registro - SP, Brasil

\section{Solange Martone Rocha e Silvana Audrá Cutolo}

Departamento de Saúde Ambiental, Faculdade de Saúde Pública, Universidade de São Paulo, Av. Dr. Arnaldo, 715, 01246-904 São Paulo - SP, Brasil

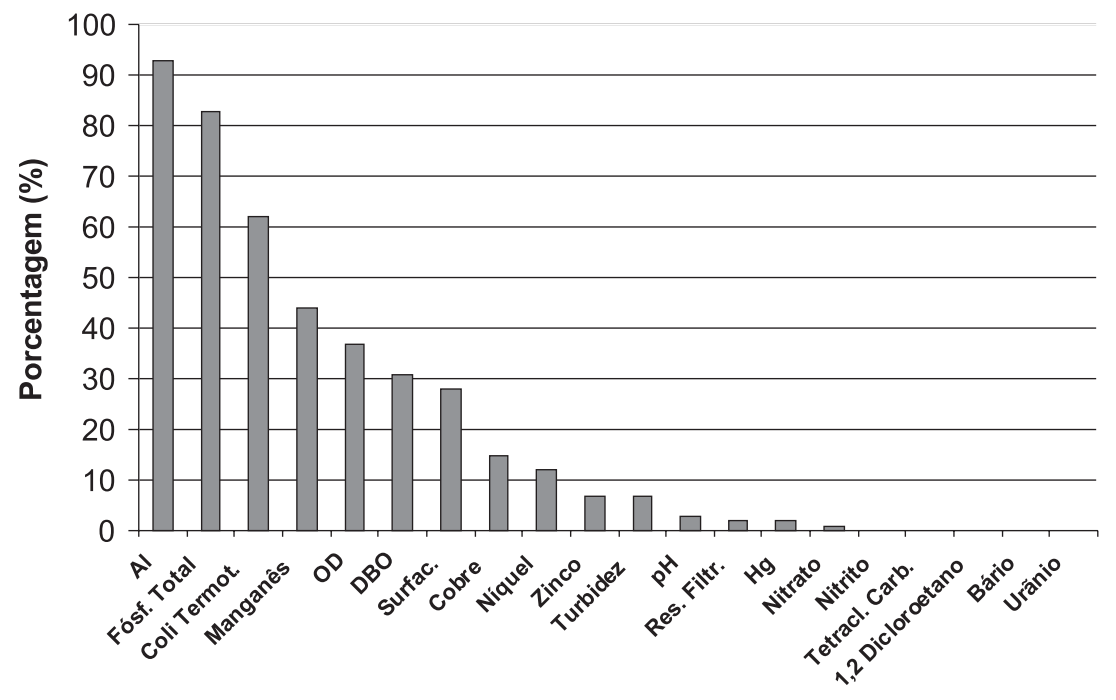

Figura 1S. Porcentagem de resultados não conformes com a Classe $2^{12}$

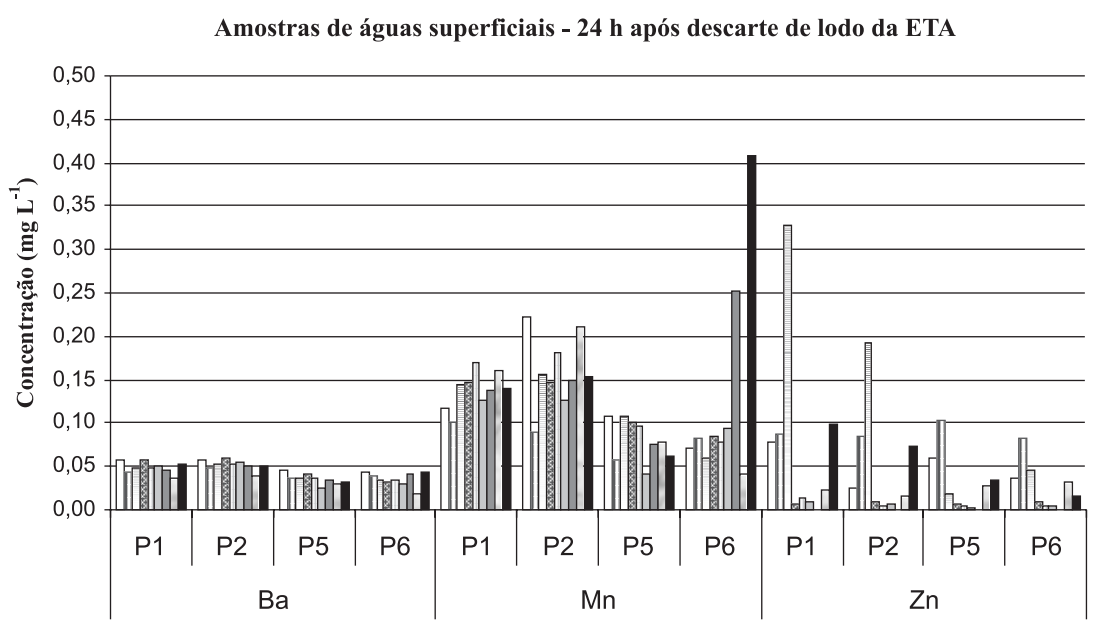

$\square \mathrm{dez} / 03 \square \mathrm{jan} / 04 \square \mathrm{fev} / 04$ 圈mar/04 $\square \mathrm{abr} / 04 \square \mathrm{mai} / 04 \square \mathrm{jun} / 04 \square \mathrm{jul} / 04 \square \mathrm{ago} / 04$

Figura 2S. Elementos traços em amostras de águas superficiais 
Variação da Concentração de Alumínio em Amostras de Sedimento Lixiviado, em Função do Índice Pluviométrico.

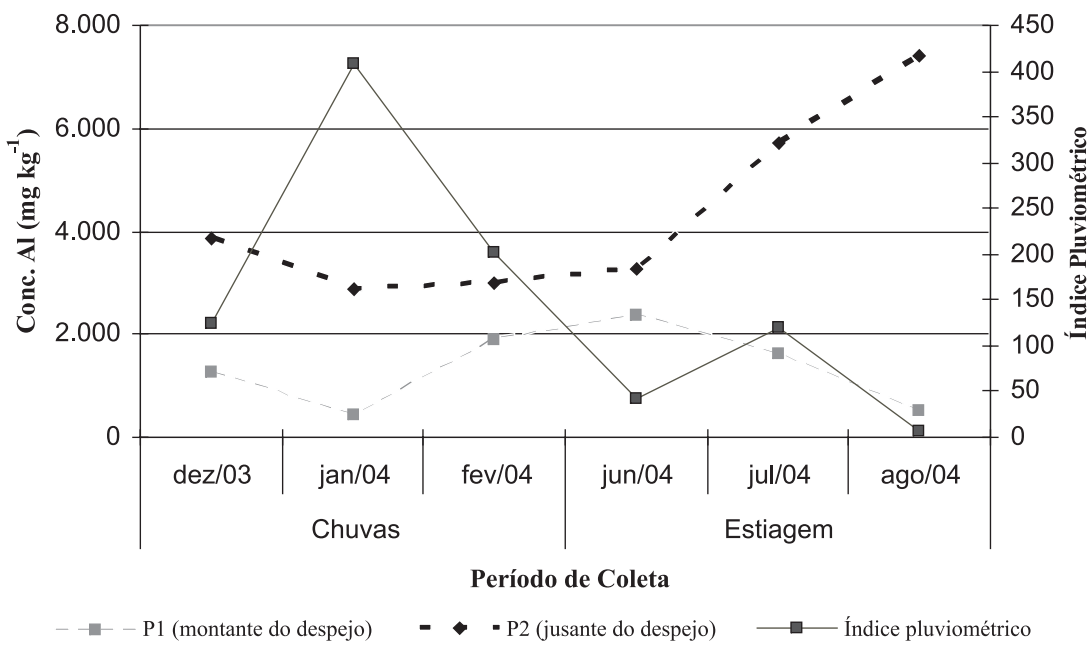

Figura 3S. Concentração de alumínio lixiviado em amostras de sedimento, em função do índice pluviométrico e período de coleta

Tabela 1S. Número de distritos brasileiros cuja água tratada passa por processo de coagulação química, por destino do lodo gerado - $2000^{2}$

\begin{tabular}{|c|c|c|c|c|c|c|c|c|}
\hline \multirow{2}{*}{$\begin{array}{l}\text { Total de } \\
\text { distritos no } \\
\text { Brasil }\end{array}$} & \multirow[b]{2}{*}{ Total } & \multicolumn{6}{|c|}{ Distritos cuja água tratada passa por processo de coagulação química } & \multirow{2}{*}{ Outro } \\
\hline & & Rio & Mar & Terreno & $\begin{array}{l}\text { estino do lodo ger } \\
\text { Aterro Sanitário }\end{array}$ & Incineracão & Reaproveitamento & \\
\hline 9.848 & 2.593 & 1888 & 10 & 482 & 35 & 2 & 39 & 189 \\
\hline
\end{tabular}

Fonte: IBGE, Diretoria de Pesquisas, Departamento de População e Indicadores Sociais, Pesquisa Nacional de Saneamento Básico 1989/2000.

Tabela 2S. Condições climáticas da cidade de Registro no período de novembro de 2003 a dezembro de 2004 e sua relação com a quantidade de sulfato de alumínio $(\mathrm{kg})$ adicionado como coagulante ${ }^{27}$

\begin{tabular}{|c|c|c|c|c|c|c|}
\hline Mês & $\begin{array}{c}\text { Temperatura } \\
\text { Máxima Mensal } \\
\left({ }^{\circ} \mathrm{C}\right)\end{array}$ & $\begin{array}{c}\text { Temperatura } \\
\text { Mínima Mensal } \\
\left({ }^{\circ} \mathrm{C}\right)\end{array}$ & $\begin{array}{c}\text { Temperatura } \\
\text { Média Mensal } \\
\left({ }^{\circ} \mathrm{C}\right)\end{array}$ & $\begin{array}{l}\text { Níveis de } \\
\text { Precipitação } \\
\quad(\mathrm{mm})\end{array}$ & $\begin{array}{c}\text { Dias } \\
\text { chuvosos }\end{array}$ & $\begin{array}{c}\text { Coagulante } \\
(\mathrm{kg})\end{array}$ \\
\hline \multicolumn{7}{|c|}{2003} \\
\hline Novembro & 28,7 & 18,9 & 23,8 & 118,6 & 12 & 19.500 \\
\hline Dezembro & 29,9 & 20,7 & 25,3 & 123,4 & 15 & 20.940 \\
\hline \multicolumn{7}{|c|}{2004} \\
\hline Janeiro & 27,7 & 20,4 & 24 & 408,4 & 16 & 28.381 \\
\hline Fevereiro & 30,2 & 20,2 & 25,2 & 200,8 & 17 & 24.576 \\
\hline Março & 28,7 & 19,6 & 24,2 & 152,9 & 16 & 19.855 \\
\hline Abril & 28,7 & 19,9 & 24,3 & 77,9 & 13 & 13.154 \\
\hline Maio & 23,6 & 15,6 & 19,6 & 78,8 & 14 & 12.862 \\
\hline Junho & 23,0 & 14,7 & 18,9 & 43,1 & 7 & 15.339 \\
\hline Julho & 22,3 & 14,0 & 18,2 & 120,7 & 14 & 15.014 \\
\hline Agosto & 24,9 & 13,6 & 19,3 & 6,3 & 7 & 11.896 \\
\hline Setembro & 27,2 & 17,7 & 22,4 & 18,1 & 7 & 14.230 \\
\hline Outubro & 26,1 & 16,7 & 21,4 & 142,3 & 12 & 18.364 \\
\hline Novembro & 27,7 & 19,3 & 23,5 & 142,4 & 15 & 18.797 \\
\hline Dezembro & 28,5 & 19,9 & 24,2 & 351,8 & 22 & 18.863 \\
\hline
\end{tabular}


Tabela 3S. Concentrações de metais e elementos-traços na fração solúvel em amostras de águas superficiais nos pontos de coleta, obtidos no período de monitoramento, 1 dia após o descarte

\begin{tabular}{|c|c|c|c|c|c|c|c|c|c|c|c|}
\hline \multirow{2}{*}{\multicolumn{2}{|c|}{$\begin{array}{l}\text { Elementos, } \\
\text { por ponto } \\
\text { de coleta }\end{array}$}} & \multirow{2}{*}{$\begin{array}{c}\text { CONAMA } \\
357 \\
0,7\end{array}$} & \multicolumn{7}{|c|}{ Concentração (mg L $\left.{ }^{-1}\right)$} & \multirow[b]{2}{*}{ Jul./04 } & \multirow[b]{2}{*}{ Ago./04 } \\
\hline & & & Dez./03 & Jan./04 & Fev./04 & Mar./04 & Abr./04 & Mai./04 & Jun./04 & & \\
\hline & $\mathrm{P} 2$ & & 0,056 & 0,047 & 0,052 & 0,059 & 0,052 & 0,056 & 0,051 & 0,040 & 0,050 \\
\hline & P5 & & 0,046 & 0,037 & 0,037 & 0,041 & 0,037 & 0,026 & 0,035 & 0,030 & 0,032 \\
\hline & P6 & & 0,043 & 0,040 & 0,035 & 0,033 & 0,034 & 0,029 & 0,042 & 0,018 & 0,043 \\
\hline \multirow{3}{*}{$\mathrm{Co}$} & $\mathrm{P} 2$ & & $<\mathrm{LQ}$ & 0,008 & 0,005 & $<\mathrm{LQ}$ & 0,014 & $<\mathrm{LQ}$ & $<\mathrm{LQ}$ & 0,013 & $<\mathrm{LQ}$ \\
\hline & P5 & & $<\mathrm{LQ}$ & 0,009 & 0,004 & $<\mathrm{LQ}$ & 0,011 & $<\mathrm{LQ}$ & $<\mathrm{LQ}$ & 0,013 & $<\mathrm{LQ}$ \\
\hline & P6 & & $<\mathrm{LQ}$ & 0,008 & 0,007 & $<\mathrm{LQ}$ & 0,011 & $<\mathrm{LQ}$ & $<\mathrm{LQ}$ & 0,013 & $<\mathrm{LQ}$ \\
\hline \multirow[t]{4}{*}{ B } & $\mathrm{P} 1$ & 0,5 & 0,014 & $<\mathrm{LQ}$ & $<\mathrm{LQ}$ & $<\mathrm{LQ}$ & 0,013 & 0,023 & 0,022 & 0,015 & 0,027 \\
\hline & $\mathrm{P} 2$ & & 0,011 & $<\mathrm{LQ}$ & $<\mathrm{LQ}$ & $<\mathrm{LQ}$ & 0,013 & 0,022 & 0,019 & 0,020 & 0,032 \\
\hline & P5 & & $<\mathrm{LQ}$ & $<\mathrm{LQ}$ & $<\mathrm{LQ}$ & $<\mathrm{LQ}$ & 0,003 & 0,006 & 0,002 & 0,012 & 0,0152 \\
\hline & P6 & & $<\mathrm{LQ}$ & $<\mathrm{LQ}$ & $<\mathrm{LQ}$ & $<\mathrm{LQ}$ & 0,003 & 0,006 & 0,002 & 0,014 & 0,0175 \\
\hline \multirow{3}{*}{$\mathrm{Al}$} & $\mathrm{P} 2$ & & 0,147 & 0,129 & 0,028 & 0,183 & 0,080 & 0,103 & 0,307 & 0,198 & 0,290 \\
\hline & P5 & & 0,124 & 0,404 & 0,037 & 0,185 & 0,196 & 0,067 & 0,157 & 0,224 & 0,169 \\
\hline & P6 & & 0,108 & 0,158 & 0,045 & 0,123 & 0,163 & 0,108 & 0,147 & 0,185 & 0,173 \\
\hline \multirow[t]{4}{*}{ V } & $\mathrm{P} 1$ & 0,1 & $<\mathrm{LQ}$ & $<\mathrm{LQ}$ & $<\mathrm{LQ}$ & $<\mathrm{LQ}$ & $<\mathrm{LQ}$ & $<\mathrm{LQ}$ & $<\mathrm{LQ}$ & $<\mathrm{LQ}$ & 0,011 \\
\hline & $\mathrm{P} 2$ & & $<\mathrm{LQ}$ & $<\mathrm{LQ}$ & $<\mathrm{LQ}$ & $<\mathrm{LQ}$ & $<\mathrm{LQ}$ & $<\mathrm{LQ}$ & $<\mathrm{LQ}$ & 0,008 & 0,012 \\
\hline & P5 & & $<\mathrm{LQ}$ & $<\mathrm{LQ}$ & $<\mathrm{LQ}$ & $<\mathrm{LQ}$ & $<\mathrm{LQ}$ & $<\mathrm{LQ}$ & $<\mathrm{LQ}$ & 0,017 & 0,015 \\
\hline & P6 & & $<\mathrm{LQ}$ & $<\mathrm{LQ}$ & $<\mathrm{LQ}$ & $<\mathrm{LQ}$ & $<\mathrm{LQ}$ & $<\mathrm{LQ}$ & $<\mathrm{LQ}$ & 0,018 & 0,0161 \\
\hline \multirow[t]{4}{*}{$\mathrm{Cr}$} & $\mathrm{P} 1$ & 0,05 & 0,007 & $<\mathrm{LQ}$ & $<\mathrm{LQ}$ & 0,027 & 0,027 & 0,032 & 0,009 & $<\mathrm{LQ}$ & 0,009 \\
\hline & $\mathrm{P} 2$ & & 0,010 & $<\mathrm{LQ}$ & 0,004 & 0,028 & 0,029 & 0,030 & 0,005 & $<\mathrm{LQ}$ & 0,011 \\
\hline & P5 & & 0,012 & $<\mathrm{LQ}$ & 0,011 & 0,031 & 0,033 & 0,033 & 0,006 & 0,008 & 0,012 \\
\hline & P6 & & 0,009 & $<\mathrm{LQ}$ & 0,012 & 0,031 & 0,041 & 0,031 & 0,006 & 0,010 & 0,0124 \\
\hline \multirow[t]{4}{*}{$\mathrm{Mn}$} & P1 & 0,1 & 0,118 & 0,101 & 0,143 & 0,146 & 0,171 & 0,126 & 0,138 & 0,161 & 0,140 \\
\hline & $\mathrm{P} 2$ & & 0,223 & 0,090 & 0,156 & 0,147 & 0,182 & 0,127 & 0,149 & 0,210 & 0,154 \\
\hline & P5 & & 0,107 & 0,058 & 0,108 & 0,102 & 0,097 & 0,040 & 0,076 & 0,077 & 0,062 \\
\hline & P6 & & 0,070 & 0,082 & 0,059 & 0,085 & 0,078 & 0,094 & 0,252 & 0,042 & 0,408 \\
\hline & P5 & & $<\mathrm{LQ}$ & $<\mathrm{LQ}$ & 0,005 & $<\mathrm{LQ}$ & 0,002 & $<\mathrm{LQ}$ & $<\mathrm{LQ}$ & 0,017 & 0,029 \\
\hline & P6 & & $<\mathrm{LQ}$ & $<\mathrm{LQ}$ & 0,004 & $<\mathrm{LQ}$ & 0,002 & $<\mathrm{LQ}$ & $<\mathrm{LQ}$ & 0,019 & 0,030 \\
\hline $\mathrm{Cu}$ & $\mathrm{P} 1$ & 0,009 & $<\mathrm{LQ}$ & $<\mathrm{LQ}$ & $<\mathrm{LQ}$ & $<\mathrm{LQ}$ & $<\mathrm{LQ}$ & $<\mathrm{LQ}$ & $<\mathrm{LQ}$ & 0,004 & $<\mathrm{LQ}$ \\
\hline & $\mathrm{P} 2$ & & $<\mathrm{LQ}$ & $<\mathrm{LQ}$ & $<\mathrm{LQ}$ & $<\mathrm{LQ}$ & $<\mathrm{LQ}$ & $<\mathrm{LQ}$ & $<\mathrm{LQ}$ & 0,005 & 0,003 \\
\hline & P5 & & $<\mathrm{LQ}$ & $<\mathrm{LQ}$ & $<\mathrm{LQ}$ & $<\mathrm{LQ}$ & $<\mathrm{LQ}$ & $<\mathrm{LQ}$ & $<\mathrm{LQ}$ & 0,015 & 0,003 \\
\hline & P6 & & $<\mathrm{LQ}$ & $<\mathrm{LQ}$ & $<\mathrm{LQ}$ & $<\mathrm{LQ}$ & $<\mathrm{LQ}$ & $<\mathrm{LQ}$ & $<\mathrm{LQ}$ & 0,016 & 0,005 \\
\hline $\mathrm{Zn}$ & P1 & 0,18 & 0,078 & 0,087 & 0,328 & 0,007 & 0,014 & 0,010 & $<\mathrm{LQ}$ & 0,023 & 0,099 \\
\hline & $\mathrm{P} 2$ & & 0,025 & 0,085 & 0,193 & 0,009 & 0,005 & 0,006 & $<\mathrm{LQ}$ & 0,016 & 0,074 \\
\hline & P5 & & 0,059 & 0,103 & 0,018 & 0,007 & 0,006 & 0,003 & $<\mathrm{LQ}$ & 0,027 & 0,036 \\
\hline & P6 & & 0,038 & 0,083 & 0,045 & 0,010 & 0,005 & 0,005 & $<\mathrm{LQ}$ & 0,033 & 0,016 \\
\hline Mo & P1 & - & 0,002 & $<\mathrm{LQ}$ & 0,012 & $<\mathrm{LQ}$ & $<\mathrm{LQ}$ & $<\mathrm{LQ}$ & $<\mathrm{LQ}$ & $<\mathrm{LQ}$ & 0,019 \\
\hline & $\mathrm{P} 2$ & & $<\mathrm{LQ}$ & $<\mathrm{LQ}$ & 0,008 & $<\mathrm{LQ}$ & $<\mathrm{LQ}$ & 0,003 & $<\mathrm{LQ}$ & $<\mathrm{LQ}$ & 0,022 \\
\hline & P5 & & $<\mathrm{LQ}$ & $<\mathrm{LQ}$ & 0,006 & $<\mathrm{LQ}$ & $<\mathrm{LQ}$ & 0,001 & $<\mathrm{LQ}$ & 0,006 & 0,020 \\
\hline & P6 & & $<\mathrm{LQ}$ & $<\mathrm{LQ}$ & 0,006 & $<\mathrm{LQ}$ & $<\mathrm{LQ}$ & $<\mathrm{LQ}$ & $<\mathrm{LQ}$ & 0,008 & 0,022 \\
\hline $\mathrm{Ag}$ & P1 & 0,01 & 0,005 & $<\mathrm{LQ}$ & 0,008 & $<\mathrm{LQ}$ & $<\mathrm{LQ}$ & $<\mathrm{LQ}$ & $<\mathrm{LQ}$ & $<\mathrm{LQ}$ & 0,011 \\
\hline & $\mathrm{P} 2$ & & $<\mathrm{LQ}$ & $<\mathrm{LQ}$ & 0,002 & $<\mathrm{LQ}$ & $<\mathrm{LQ}$ & $<\mathrm{LQ}$ & $<\mathrm{LQ}$ & $<\mathrm{LQ}$ & 0,012 \\
\hline & P5 & & $<\mathrm{LQ}$ & $<\mathrm{LQ}$ & 0,047 & $<\mathrm{LQ}$ & $<\mathrm{LQ}$ & $<\mathrm{LQ}$ & $<\mathrm{LQ}$ & 0,006 & 0,015 \\
\hline & P6 & & $<\mathrm{LQ}$ & $<\mathrm{LQ}$ & 0,049 & $<\mathrm{LQ}$ & $<\mathrm{LQ}$ & $<\mathrm{LQ}$ & $<\mathrm{LQ}$ & 0,009 & 0,016 \\
\hline $\mathrm{Cd}$ & P1 & 0,001 & $<\mathrm{LQ}$ & $<\mathrm{LQ}$ & 0,001 & $<\mathrm{LQ}$ & 0,001 & 0,002 & $<\mathrm{LQ}$ & $<\mathrm{LQ}$ & 0,009 \\
\hline & $\mathrm{P} 2$ & & $<\mathrm{LQ}$ & $<\mathrm{LQ}$ & 0,002 & $<\mathrm{LQ}$ & 0,001 & 0,002 & $<\mathrm{LQ}$ & $<\mathrm{LQ}$ & 0,010 \\
\hline & P5 & & $<\mathrm{LQ}$ & $<\mathrm{LQ}$ & 0,002 & $<\mathrm{LQ}$ & 0,001 & 0,002 & $<\mathrm{LQ}$ & 0,004 & 0,010 \\
\hline & P6 & & $<\mathrm{LQ}$ & $<\mathrm{LQ}$ & 0,002 & $<\mathrm{LQ}$ & 0,001 & 0,001 & $<\mathrm{LQ}$ & 0,005 & 0,011 \\
\hline $\mathrm{Sn}$ & $\mathrm{P} 1$ & - & $<\mathrm{LQ}$ & $<\mathrm{LQ}$ & 0,017 & $<\mathrm{LQ}$ & $<\mathrm{LQ}$ & 0,006 & $<\mathrm{LQ}$ & $<\mathrm{LQ}$ & $<\mathrm{LQ}$ \\
\hline & $\mathrm{P} 2$ & & $<\mathrm{LQ}$ & $<\mathrm{LQ}$ & 0,08 & $<\mathrm{LQ}$ & 0,020 & 0,010 & $<\mathrm{LQ}$ & $<\mathrm{LQ}$ & $<\mathrm{LQ}$ \\
\hline & P5 & & $<\mathrm{LQ}$ & $<\mathrm{LQ}$ & 0,024 & $<\mathrm{LQ}$ & 0,017 & 0,011 & $<\mathrm{LQ}$ & $<\mathrm{LQ}$ & $<\mathrm{LQ}$ \\
\hline & P6 & & $<\mathrm{LQ}$ & $<\mathrm{LQ}$ & 0,020 & $<\mathrm{LQ}$ & 0,014 & 0,010 & $<\mathrm{LQ}$ & $<\mathrm{LQ}$ & $<\mathrm{LQ}$ \\
\hline $\mathrm{Pb}$ & P1 & 0,01 & 0,001 & 0,002 & $<0,001$ & 0,001 & 0,001 & $*$ & $<0,001$ & $*$ & $*$ \\
\hline & $\mathrm{P} 2$ & & 0,002 & $<0,001$ & $<0,001$ & $<0,001$ & $<0,001$ & $*$ & $<0,001$ & $*$ & $*$ \\
\hline & P5 & & 0,003 & 0,003 & 0,004 & 0,004 & 0,004 & $*$ & $<0,001$ & $*$ & $*$ \\
\hline & P6 & & 0,002 & 0,004 & 0,003 & 0,002 & 0,003 & $*$ & $<0,001$ & $*$ & $*$ \\
\hline
\end{tabular}


Tabela 4S. Abundância relativa da comunidade bentônica no período de estudo, realizadas antes e depois do descarte de lodo da ETA

\begin{tabular}{|c|c|c|c|c|c|c|}
\hline \multirow[t]{4}{*}{ Organismo } & \multicolumn{6}{|c|}{ Ponto 1} \\
\hline & \multicolumn{2}{|c|}{$1^{\mathrm{a}}$ Coleta } & \multicolumn{2}{|c|}{$2^{\mathrm{a}}$ Coleta } & \multicolumn{2}{|c|}{$3^{\mathrm{a}}$ Coleta } \\
\hline & $\begin{array}{l}\text { Antes do } \\
\text { descarte }\end{array}$ & $\begin{array}{l}\text { Depois do } \\
\text { descarte }\end{array}$ & $\begin{array}{l}\text { Antes do } \\
\text { descarte }\end{array}$ & $\begin{array}{l}\text { Depois do } \\
\text { descarte }\end{array}$ & $\begin{array}{l}\text { Antes do } \\
\text { descarte }\end{array}$ & $\begin{array}{c}\text { Depois do } \\
\text { descarte }\end{array}$ \\
\hline & $21 / 9 / 2004$ & $23 / 9 / 2004$ & $20 / 10 / 2004$ & $22 / 10 / 2004$ & $5 / 4 / 2005$ & $7 / 4 / 2005$ \\
\hline Mollusca-Pelecypoda & 0 & 0 & 0 & 0 & 1 & 0 \\
\hline Insecta-Diptera-Chironomidae & 101 & 850 & 5 & 1 & 0 & 0 \\
\hline Annelida-Oligochaeta-Tubificidae & 3 & 0 & 0 & 0 & 0 & 0 \\
\hline Annelida-Hirudinea & 0 & 0 & 0 & 1 & 0 & 0 \\
\hline \multirow[t]{4}{*}{ Organismo } & \multicolumn{6}{|c|}{ Ponto 2} \\
\hline & \multicolumn{2}{|c|}{$1^{\mathrm{a}}$ Coleta } & \multicolumn{2}{|c|}{$2^{\mathrm{a}}$ Coleta } & \multicolumn{2}{|c|}{$3^{\mathrm{a}}$ Coleta } \\
\hline & $\begin{array}{l}\text { Antes do } \\
\text { descarte }\end{array}$ & $\begin{array}{c}\text { Depois do } \\
\text { descarte }\end{array}$ & $\begin{array}{l}\text { Antes do } \\
\text { descarte }\end{array}$ & $\begin{array}{l}\text { Depois do } \\
\text { descarte }\end{array}$ & $\begin{array}{l}\text { Antes do } \\
\text { descarte }\end{array}$ & $\begin{array}{c}\text { Depois do } \\
\text { descarte }\end{array}$ \\
\hline & $21 / 9 / 2004$ & $23 / 9 / 2004$ & $20 / 10 / 2004$ & $22 / 10 / 2004$ & $5 / 4 / 2005$ & $7 / 4 / 2005$ \\
\hline Mollusca-Gastropoda & 1 & 3 & 0 & 0 & 0 & 0 \\
\hline Annelida-Hirudinea & 1 & 0 & 0 & 0 & 0 & 0 \\
\hline \multirow[t]{4}{*}{ Organismo } & \multicolumn{6}{|c|}{ Ponto 3} \\
\hline & \multicolumn{2}{|c|}{$1^{\mathrm{a}}$ Coleta } & \multicolumn{2}{|c|}{$2^{\mathrm{a}}$ Coleta } & \multicolumn{2}{|c|}{$3^{\text {a }}$ Coleta } \\
\hline & $\begin{array}{l}\text { Antes do } \\
\text { descarte }\end{array}$ & $\begin{array}{c}\text { Depois do } \\
\text { descarte }\end{array}$ & $\begin{array}{l}\text { Antes do } \\
\text { descarte }\end{array}$ & $\begin{array}{l}\text { Depois do } \\
\text { descarte }\end{array}$ & $\begin{array}{l}\text { Antes do } \\
\text { descarte }\end{array}$ & $\begin{array}{c}\text { Depois do } \\
\text { descarte }\end{array}$ \\
\hline & $21 / 9 / 2004$ & $23 / 9 / 2004$ & $20 / 10 / 2004$ & $22 / 10 / 2004$ & $5 / 4 / 2005$ & $7 / 4 / 2005$ \\
\hline Mollusca-Gastropoda & 1 & 0 & 7 & 0 & $*$ & $*$ \\
\hline \multirow[t]{4}{*}{ Organismo } & \multicolumn{6}{|c|}{ Ponto 4} \\
\hline & \multicolumn{2}{|c|}{$1^{\mathrm{a}}$ Coleta } & \multicolumn{2}{|c|}{$2^{\mathrm{a}}$ Coleta } & \multicolumn{2}{|c|}{$3^{\mathrm{a}}$ Coleta } \\
\hline & $\begin{array}{l}\text { Antes do } \\
\text { descarte }\end{array}$ & $\begin{array}{c}\text { Depois do } \\
\text { descarte }\end{array}$ & $\begin{array}{l}\text { Antes do } \\
\text { descarte }\end{array}$ & $\begin{array}{l}\text { Depois do } \\
\text { descarte }\end{array}$ & $\begin{array}{l}\text { Antes do } \\
\text { descarte }\end{array}$ & $\begin{array}{c}\text { Depois do } \\
\text { descarte }\end{array}$ \\
\hline & $21 / 9 / 2004$ & $23 / 9 / 2004$ & $20 / 10 / 2004$ & $22 / 10 / 2004$ & $5 / 4 / 2005$ & $7 / 4 / 2005$ \\
\hline Mollusca-Gastropoda & 0 & 2 & 0 & 0 & 0 & 0 \\
\hline Insecta-Diptera-Chironomidae & 7 & 0 & 0 & 1 & 0 & 0 \\
\hline Annelida-Oligochaeta-Tubificidae & 9 & 0 & 0 & 0 & 0 & 0 \\
\hline \multirow[t]{4}{*}{ Organismo } & \multicolumn{6}{|c|}{ Ponto 5} \\
\hline & \multicolumn{2}{|c|}{$1^{\mathrm{a}}$ Coleta } & \multicolumn{2}{|c|}{$2^{\mathrm{a}}$ Coleta } & \multicolumn{2}{|c|}{$3^{\mathrm{a}}$ Coleta } \\
\hline & $\begin{array}{l}\text { Antes do } \\
\text { descarte }\end{array}$ & $\begin{array}{c}\text { Depois do } \\
\text { descarte }\end{array}$ & $\begin{array}{l}\text { Antes do } \\
\text { descarte }\end{array}$ & $\begin{array}{l}\text { Depois do } \\
\text { descarte }\end{array}$ & $\begin{array}{l}\text { Antes do } \\
\text { descarte }\end{array}$ & $\begin{array}{c}\text { Depois do } \\
\text { descarte }\end{array}$ \\
\hline & $21 / 9 / 2004$ & $23 / 9 / 2004$ & $20 / 10 / 2004$ & $22 / 10 / 2004$ & $5 / 4 / 2005$ & $7 / 4 / 2005$ \\
\hline Insecta-Diptera-Chironomidae & 2 & 0 & 0 & 0 & 0 & 0 \\
\hline Insecta-Ephemeroptera & 1 & 0 & 0 & 0 & 0 & 0 \\
\hline Annelida-Oligochaeta-Tubificidae & 5 & 4 & 3 & 0 & 0 & 0 \\
\hline Organismo & & & & o 6 & & \\
\hline & & leta & & leta & & leta \\
\hline & $\begin{array}{l}\text { Antes do } \\
\text { descarte }\end{array}$ & $\begin{array}{c}\text { Depois do } \\
\text { descarte }\end{array}$ & $\begin{array}{l}\text { Antes do } \\
\text { descarte }\end{array}$ & $\begin{array}{c}\text { Depois do } \\
\text { descarte }\end{array}$ & $\begin{array}{l}\text { Antes do } \\
\text { descarte }\end{array}$ & $\begin{array}{c}\text { Depois do } \\
\text { descarte }\end{array}$ \\
\hline & $21 / 9 / 2004$ & $23 / 9 / 2004$ & $20 / 10 / 2004$ & $22 / 10 / 2004$ & $5 / 4 / 2005$ & $7 / 4 / 2005$ \\
\hline Insecta-Diptera-Chironomidae & 1 & 0 & 0 & 0 & 0 & 0 \\
\hline Insecta-Diptera-Ceratopogonidae & 0 & 2 & 0 & 0 & 0 & 0 \\
\hline Insecta-Ephemeroptera & 0 & 9 & 0 & 0 & 0 & 0 \\
\hline Annelida-Oligochaeta-Tubificidae & 2 & 2 & 0 & 0 & 0 & 0 \\
\hline
\end{tabular}

